\begin{tabular}{|c|c|c|}
\hline 4 & $\begin{array}{c}\text { European Association for the } \\
\text { Development of Renewable Energies, Environment } \\
\text { and Power Quality (EA4EPQ) }\end{array}$ & $\begin{array}{l}\text { International Conference on Renewable Energies and Power Quality } \\
\text { (ICREPQ'12) } \\
\text { Santiago de Compostela (Spain), 28th to 30th March, } 2012\end{array}$ \\
\hline
\end{tabular}

\title{
Matlab based Model of 40-MW Concentrating Solar Power Plant
}

\author{
Silvano Vergura, Virginio Di Fronzo \\ Department of Electrotechnics \\ Politecnico di Bari, \\ St. E. Orabona, 4, 70125 Bari (Italy) \\ Phone/Fax number:+0039080 5963590, e-mail: vergura@poliba.it
}

\begin{abstract}
The paper proposes the Matlab based model of a Concentrating Solar Power plant (CSP), rated of $40 \mathrm{MW}$. The modelled system considers the technology of parabolic through and follows the layout of a pilot project, to be realized in the south of Italy. As that project contains also the thermal storage, the input and output temperature are well-defined. The conversion to the electrical energy is obtained by a common fossil fuel power station. Then only the primary loop of the whole system has been considered for the proposed model. The model allows to evaluate the thermal performance and the thermal eficiency of the primary loop constituting a CSP.
\end{abstract}

\section{Key words}

Concentrating Solar Plant, Matlab model, thermal storage.

\section{Introduction}

The $\mathrm{CO}_{2}$ emissions are considered responsible of the climate changes for the Earth. As these emissions are produced also by burning the fossil fuels to produce electrical energy, many countries in the world are transforming their national electrical production systems, decreasing the electrical production deriving from fossil fuels and increases that one deriving from Renewable Energy Sources (RES). Among RES, solar technologies are capturing large interest. Moreover, the green paper of the Commission of the European Communities [1] reports that half of the EU's gas consumption went from only three countries (Russia, Norway, Algeria) and the oil and gas prices had nearly doubled in the EU over the past two years, with electricity prices following. Then, the EU strategy for the energy is to reach the target of $20 \%$ of produced energy by RES within 2020 . This paper focuses the attention on CSP because they are acquiring an increasing interest, especially if built with thermal energy storage [2]-[3]-[4]. Moreover, economic issues have been treated for CSP in order to verify which are the profit, the breakeven and so on [5].

The CSPs can be categorized into three main technologies, based on the process of collecting and concentrating solar radiation [6]: a) Parabolic Trough, b) Solar Tower for Central Receiver, c) Parabolic Dish. It exists also a forth technology (Linear Fresnel Reflector), but it is less common than the previous ones.
The first one uses parabolic trough shaped mirrors to concentrate the incident Direct Normal Irradiation (DNI) onto a receiver tube which is placed at the focal line of the trough. This is the most commercial technology for CSPs because it is the most mature technology. As this technology is considered in the paper, an in depth description is reported in the next section.

In Solar Tower technology the solar collector field contains a radial arrangement of several sun tracking large mirrors that concentrate the solar energy onto the receiver placed on the top of a central tower.

The third technology uses a parabolic dish-shaped solar concentrator that concentrates the sunlight onto a receiver placed at the focal point of the dish.

The paper is organized as follows: Section 2 reports a description of CSP under test, Section 3 presents the Matlab based model and Section 4 discusses the results.

\section{Description of the CSP under test}

This paper focuses the attention on the CSP based on parabolic through. An Italian pilot project, based on this technology, has been realized by ENEL (Italy's largest power utility) and ENEA (Italian National agency for new technologies, Energy and sustainable economic development) in the south of Italy, named Archimede.

The CSP model proposed in this paper has utilized Archimede as referecnce. The sub-section A presents the components, while the sub-section B describes the layout of the implemented model.

\section{A. Components and operation of the CSP}

The CSP under investigation is constituted by the following main components:

- linear parabolic trough-shaped mirrors to focus sun's rays onto a receiver pipe running along the focal line and containing a flowing fluid (Fig. 1), named collectors;

- hydraulic circuit with molten salts that connects the field of reflectors and the storage system, including the control system for controlling the temperature of the salts and the devices for loading and unloading of the salts;

- $\quad$ pumping systems of the salts; 
- $\quad$ storage system made of two tanks with a circular section;

- electrical power station equipped with two steam turbines (high and low pressure, respectively), a molten salt steam generator, a condenser with an appropriate cooling system (water or air) and the feed water preheating system.

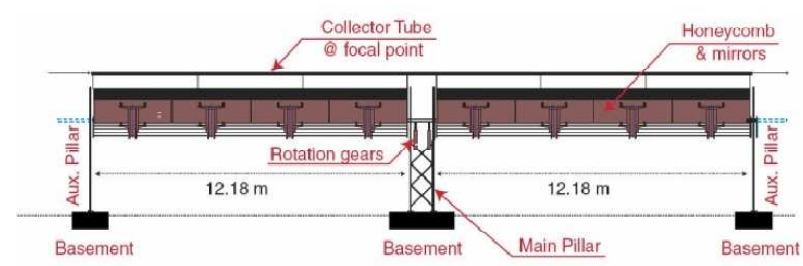

(a)

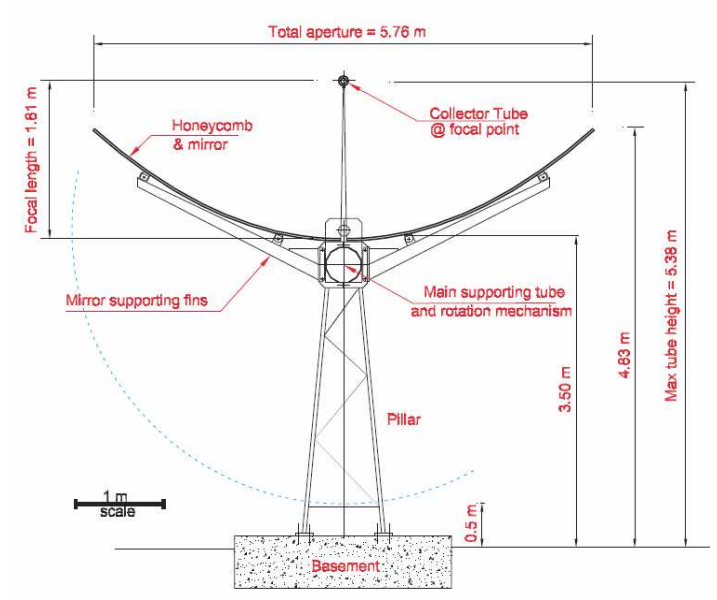

(b)

Fig. 1. Reflectors with receiver pipe

The reflectors concentrates the sun's rays on the receiver and the heated fluid is transported to the energy conversion system. During this step a part of the fluid can be stored for a successive use. Then the remaining part is utilized to produce electrical energy. The energy conversion system is similar to a common fossil fuel plant utilizing a thermal steam Rankine cycle. Usually, a mineral oil is used but it is expensive and highly flammable, then it can lead to important problems if it leaks at the operating temperature $\left(290-390^{\circ} \mathrm{C}\right)$. For these reasons, it has been considered a fluid constituted by a mixture of salts, sodium and potassium nitrate; this fluid is largely used in the industry because chemically stable until $600^{\circ} \mathrm{C}$ and without corrosion problems. Moreover, the thermal storage allows to store the solar energy which can be used when it is not present (by night, in presence of clouds and so on). This is a very important task for each solar plant. In fact the unpredictability of the energy production is the main disadvantage of solar plants, which are usually used by the detractors of the solar energy plants. The thermal storage allows to decouple the collect of the thermal energy from the electrical energy production, i.e. it is not needed to produce and to use the electrical energy just when the thermal energy is collected. In this way it is possible to have a more efficient operation of the electrical generator eliminating the stops due to cloudiness and making the system more compatible with the demands of the electricity grid. Fig. 2 reports a simplified scheme of the CSP. Three circuits are present:

1. primary loop, devoted to the harvesting, distribution and storage of the solar thermal energy;

2. secondary loop, where the thermal energy stored in the hot tank is utilized into the steam generator;

3. thermal cycle, where the thermal energy is transformed in the electrical one.

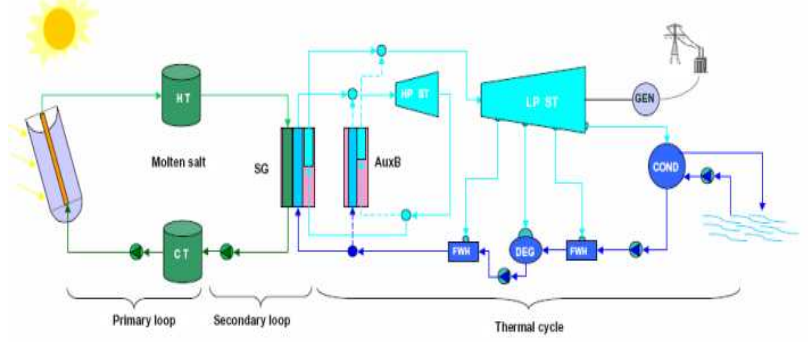

Fig. 2 CSP under investigation

The operation principle of the CSP under investigation is the following.

When direct solar radiation is present, the thermal fluid, taken from the cold tank at the temperature of $290^{\circ} \mathrm{C}$, flows into the receivers and heats up until $550{ }^{\circ} \mathrm{C}$. Then, it is pumped in the hot tank where it is stored. The flow capacity of the molten salts into the primary circuit is adjusted with respect to the solar radiation in order to maintain constant the input temperature of the hot tank. As the molten salts have high temperature of solidification $\left(238^{\circ} \mathrm{C}\right)$, it is needed to maintain a minimum flow capacity when the solar radiation is not present or to provide heating systems of the pipes in order to avoid that the fluid temperature falls below it.

When electrical energy is requested, the salts stored into the hot tank are pumped into the heat exchanger, where the steam at high pressure and temperature is produced. Then, the molten salts are collected into the cold tank. As already said, the thermal cycle is similar to a common fossil fuel power station. Two turbines for high and low pressure are present (Fig. 2), while the superheated steam has temperature of $525^{\circ} \mathrm{C}$ and pressure of 120 bar when it expands through the high pressure turbine. The electrical rated power of the CSP is $40 \mathrm{MW}$, while the efficiency of the thermal cycle is equal to $42.3 \%$. A detailed representation of the thermal cycle is reported in Fig. 3a, while Fig. 3b represents the TemperatureEntropy diagram. The numeration in the upper figure allows to understand the successive steps of the fluid, while the lower figure highlights the temperature value at each corresponding step.

\section{B. Layout of the collectors and characteristic parameters}

Fig. 4 reports the layout of the modeled CSP. It can be observed that the thermal power station (turbines, steam generator, condenser, tanks) is in central position while the solar field is constituted by 3 areas: 2 of them containing 33 Solar Collector Assembly (SCA) and the third one containing 70 SCA. The SCA are parallelconnected each other. Each SCA of each area is 
constituted by 6 series-connected collectors and each collector is $100 \mathrm{~m}$ long and has a span of $5.76 \mathrm{~m}$. Then, one SCA is $600 \mathrm{~m}$ long while the distance between two SCA is equal to 2 times the span of a collector. Table 1 reports the main parameters of the CSP.
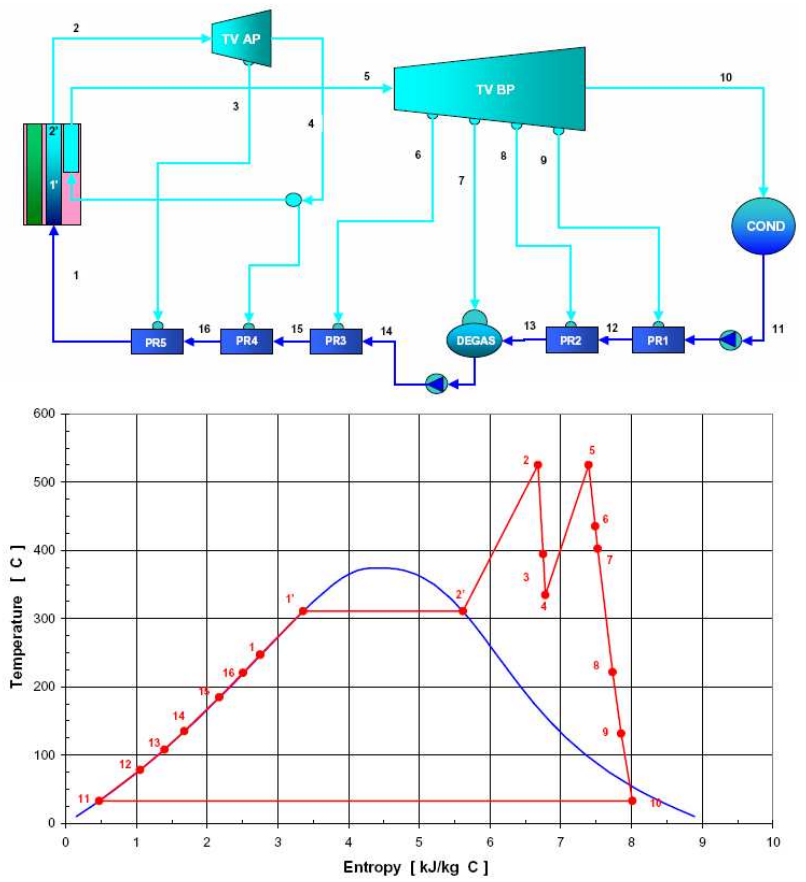

Fig. 3. Thermal cycle (a) and T-E diagram (b).
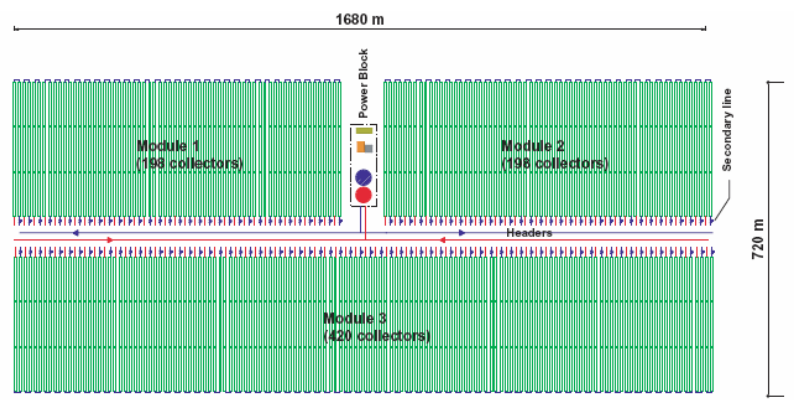

Fig. 4. Layout of the CSP

\section{Matlab based model of the CSP}

Unlike a PV plant for which all the three components of solar radiation (direct one, diffuse one and reflected one) are useful for the energy production, the CSP utilizes only the direct component. For this aim it is needed to know the DNI for the installation site. In this model we consider that the CSP is plant up in Bari, a city of the South of Italy different from the installation site of the ENEA's project. The values of DNI for Bari are not available, but in mediterranean countries the values of the DNI are similar to the values of the Global Horizontal Insolation (GHI), as reported in Fig. 5; then GHI values are utilized for this paper. Fig. 6 reports a comparison between the GHI of the installation site of the ENEA's project (Gela) and the same variable referred to the city of Bari. It can be seen as that the curve of Bari is always below the curve of Gela.

Table 1 - Parameters of the CSP

\begin{tabular}{|l|l|}
\hline Number of the collectors & 816 \\
\hline Area of each collector & $3317.76 \mathrm{~m}^{2}$ \\
\hline Total collector area & $45^{*} 10^{4} \mathrm{~m}^{2}$ \\
\hline Distance between collectors & $11.5 \mathrm{~m}$ \\
\hline $\begin{array}{l}\text { Peak power of the solar field (with } \\
\text { radiation of 900W/m } / \mathrm{m}^{2} \text { and efficiency of } \\
\text { the collector equal to 0.79) }\end{array}$ & $321 \mathrm{MWt}$ \\
\hline Solar field area & $90 \mathrm{ha}$ \\
\hline Temperature of the hot tank & $550^{\circ} \mathrm{C}$ \\
\hline Temperature of the cold tank & $290{ }^{\circ} \mathrm{C}$ \\
\hline Storage capacity & $3000 \mathrm{MWh}$ \\
\hline Rated electrical power & $40 \mathrm{MWe}$ \\
\hline $\begin{array}{l}\text { Thermo-electrical efficiency in rated } \\
\text { electrical }\end{array}$ & 0.423 \\
\hline Produced energy for year & $168 \mathrm{GWh} /$ year \\
\hline $\begin{array}{l}\text { Load factor (ratio between produced } \\
\text { energy and energy obtained if the CSP } \\
\text { works in the rated conditions during the } \\
\text { whole year) }\end{array}$ & 0.48 \\
\hline $\begin{array}{l}\text { Mean collector efficiency for year } \\
\text { (depending on the annual direct } \\
\text { radiation) }\end{array}$ & 0.67 \\
\hline
\end{tabular}

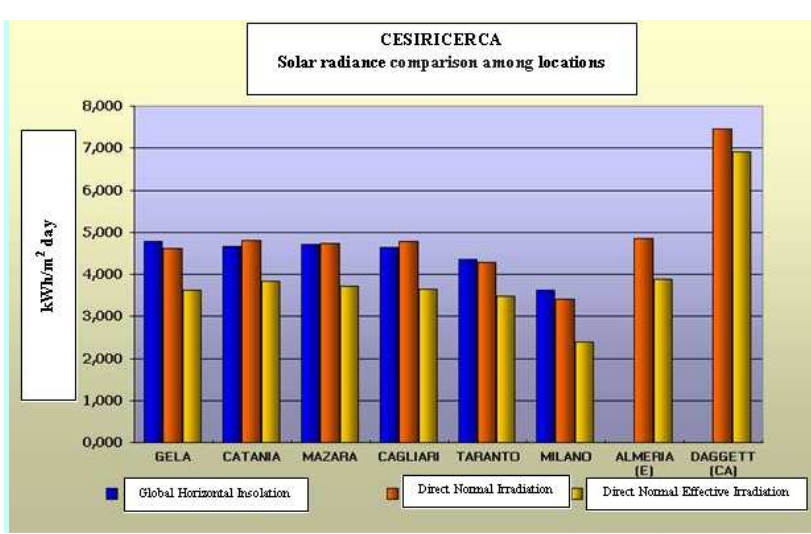

Fig. 5. Comparison between GHI and DNI

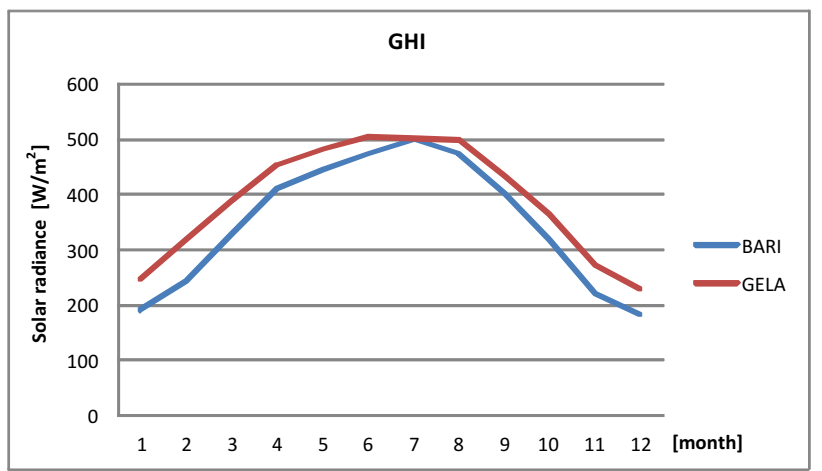

Fig. 6. Comparison between solar radiance of Gela and Bari. 


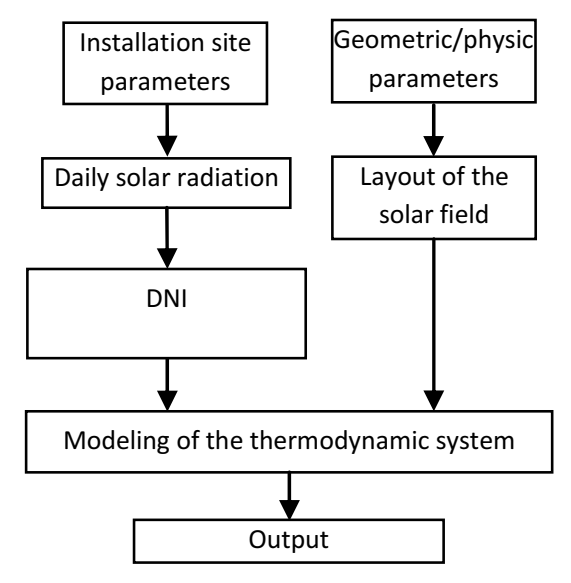

Fig. 7 Modeling steps of primary loop of Fig. 2

As the secondary loop and thermal cycle of Fig. 2 represent the standard operation of a common fossil fuel power station utilizing a Rankine cycle, the model proposed in this paper is limited to the only primary loop, i.e. the thermodynamic system. Fig. 7 reports the steps for modeling the primary loop of Fig. 2. It can be noted that two sets of input data are necessary. The former one regards the installation site: latitude, altitude, climate conditions, available surface, shadings and so on. The latter one is constituted by the geometric dimensions of each collector, number of collectors (depending on the desired electrical power), number of SCAs, typology of fluid and so on. The first set of input data allows to determine the DNI while the second one allows to define the layout of the solar field. Finally, a mathematical model of the thermodynamic system is obtained, considering the fluid starting from the cold tank and arriving to the hot one, flowing through the receivers network. The output data of the model are the thermal efficiency, the thermal power and the final fluid temperature, i.e. the temperature of the fluid just when it is stored in the hot tank. This last one is evaluated as:

$$
T_{U}=T_{I}+\frac{Q_{\text {fluid }}}{G_{s} \cdot c_{p s}}
$$

where $T_{U}$ is the final temperature, $T_{I}$ is the initial temperature (i.e. the fluid temperature from the cold tank), $\mathrm{Q}_{\text {fluid }}$ the thermal power of the fluid, $\mathrm{G}_{\mathrm{s}}$ the flow capacity and $c_{p s}$ the specific heat of the molten salts. It can be noted that $T_{U}$ decreases as $G_{s}$ increases: the larger the flow capacity the shorter the time necessary to pass through the receiver. $\mathrm{Q}_{\text {fluid }}$ is calculated as:

$$
Q_{\text {fluid }}=\eta \cdot I_{\text {direct }} \cdot A
$$

where $\mathrm{A}$ is the reflector surface, $\mathrm{I}_{\text {direct }}$ the direct radiation and $\eta$ the global efficiency taking into account the losses, the pointing system and so on.

\section{Results}

After modeling the thermodynamic system, some simulations have been run in Matlab environment in order to evaluate its thermal performance and efficiency. For this aim several input variables have been considered. In fact, the thermal performance (i.e. the final temperature of the molten salts, $\mathrm{T}_{\mathrm{U}}$ ) depends on the length of a single collector, on its flow capacity and on the radiation. As the SCA are equal each other, all the successive figures and evaluations are referred to a single SCA.

Fig. 8 reports $T_{U}=f\left(G_{S}\right)$ for several values of radiation. As it can be seen, for a fixed value of $G_{S}, \mathrm{~T}_{\mathrm{U}}$ has a positive correlation with the radiation, i.e. the thermal performance increases as $I_{\text {direct }}$ increases. Then the correlation between $T_{U}$ and $G_{S}$ is opposite respect to the correlation between $T_{U}$ and $I_{\text {direct }}$.

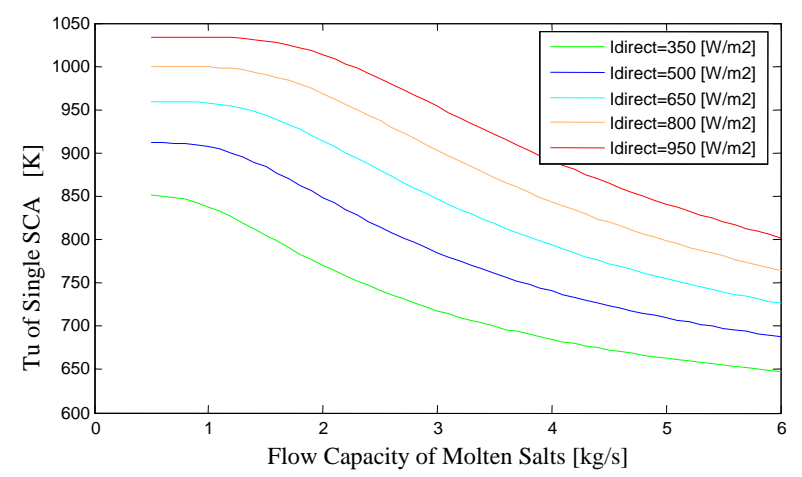

Fig. 8 Thermal performance of a single SCA respect to the flow capacity

Fig. 9 reports the final temperature $T_{U}=f\left(l_{s}\right)$, where $l_{s}$ represents the length of a single SCA, for different values of the flow capacity $G_{s}$. It can be noted that, for $G_{s} \geq 3 \mathrm{~kg} / \mathrm{s}, \quad \mathrm{T}_{\mathrm{U}}$ increases linearly as $l_{s}$ increases, whereas for $G_{s}<3 \mathrm{~kg} / \mathrm{s}$, the correlation between $\mathrm{T}_{\mathrm{U}}$ and $l_{s}$ is yet positive but nonlinear. Fig. 9 has been obtained considering $I_{\text {direct }}=350 \mathrm{~W} / \mathrm{m}^{2}$; similar figures are obtained for different values of $I_{\text {direct }}$.

Fig. 10 represents the thermal efficiency of a single SCA with respect to the length of the SCA. Obviously, the efficiency decreases as $l_{s}$ increases because of the losses along the pipe; nevertheless, for higher values of $\mathrm{G}_{\mathrm{s}}(5-6 \mathrm{~kg} / \mathrm{s})$ the decrease is limited also for very long SCA $(600 \mathrm{~m})$. Instead, efficiency decreases quickly for lower values of $\mathrm{G}_{\mathrm{s}}$ as $l_{s}$ increases. Moreover, for the smallest value of $G_{s}$, the relation is nonlinear. Also Fig. 10 is obtained for $I_{\text {direct }}=350 \mathrm{~W} / \mathrm{m}^{2}$ and similar figures are obtained for different values of $I_{\text {direct }}$.

Finally, Fig. 11 diagrams the thermal power depending on the flow capacity of the molten salts, for a fixed value of $\mathrm{I}_{\text {direct }}$. Also in this case, the relation is linear for the higher values of $\mathrm{G}_{\mathrm{s}}$, otherwise nonlinear.

The previous analyses highlight that the control of the CSP is not trivial as the output parameters have opposite correlations with respect to the input data, e.g. flow capacity, length of the SCA, direct radiation. For example, Fig. 10 suggest to use shortest SCA, but it is not possible if high electrical power is requested.

\section{Conclusions}

This paper has proposed a Matlab based model of the primary loop of a CSP. The model is based on a real CSP located in South of Italy, but another installation site has 
been considered. In this paper the secondary loop and the electrical energy production cycle have not been considered as they follow a standard common fossil fuel power station. Respect to the only priamy loop, the model has allowed to verify that a suitable range of flow capacity have to be imposed if a linear operation is desired. Anyway, the control aspects result very important in order to obatin an optimal efficiency of the CSP. This typology of CSP is very interesting because the typical problems of solar plants (unpredictability of the energy production) are overcome by means of a couple of tanks, the hot one and the cold one. The hot tank represents the storage of the thermal energy to be used also when the radiation is not present or is not sufficient.

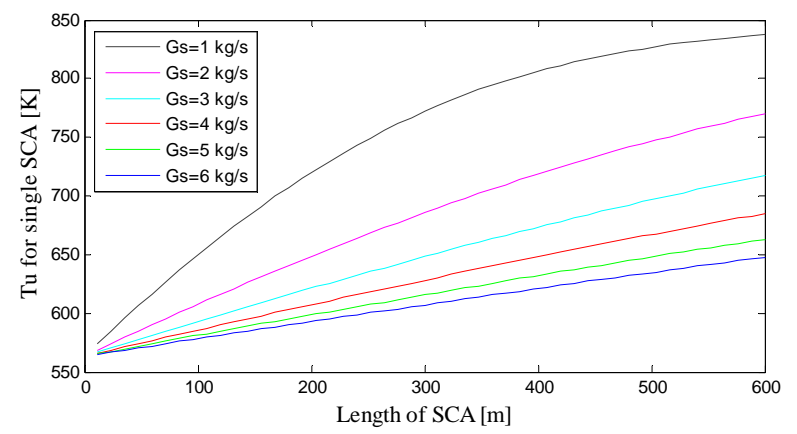

Fig. 9 Thermal performance of a single SCA respect to the length of the receiver

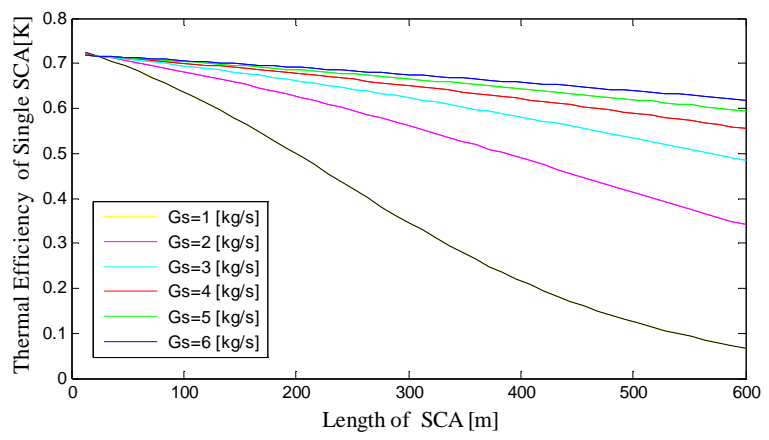

Fig. 10 Thermal efficiency of a single SCA respect to the length of the SCA.

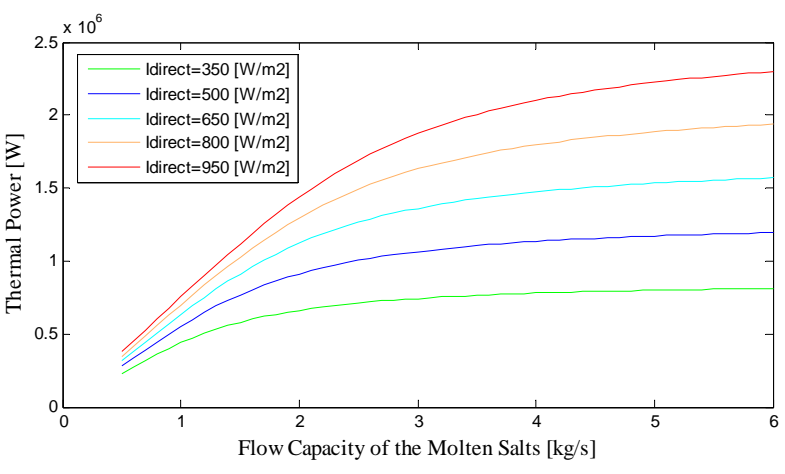

Fig. 11 Thermal power of a single SCA respect to the flow capacity of the molten salts

\section{References}

[1] Commission of the european communities, GREEN PAPER - A European Strategy for Sustainable, Competitive and Secure Energy, 2006, http://europa.eu/documents/comm/green_papers/pdf/com 2006_105_en.pdf

[2] U. Herrmann and D. W. Kearney, "Survey of thermal energy storage for parabolic trough power plants," J. Solar Energy Eng., vol. 124, pp. 145-152, May 2002.

[3] V. Morisson, M. Rady, E. Palomo, and E. Arquis, "Thermal energy storage systems for electricity production using solar energy direct steam generation technology," Chem. Eng. Process., Process Intensification, vol. 47, pp. 499-507, Mar. 2008.

[4] M. Medrano, A. Gil, I. Martorell, X. Potau, and L. F. Cabeza, "State of the art on high-temperature thermal energy storage for power genera-tion. Part 2-Case studies," Renewable Sustainable Energy Rev., vol. 14, pp. 56-72, Jan. 2010.

[5] R. Sioshansi, P. Denholm., The Value of Concentrating Solar Power and Thermal Energy Storage, IEEE Trans. on Sustainable Energy, Vol. 1, n.3, 2010, pp. 173-183.

[6] G. Glatzmaier, Summary Report for Concentrating Solar Power Thermal Storage Workshop, NREL, 2011. 